\title{
Optimización de la extracción de ADN de Passiflora ligularis para el análisis por medio de marcadores moleculares
}

\author{
Gina Solano-Flórez, María del Pilar Márquez-Cardona*, Ingrid Schuler \\ Unidad de Biotecnología Vegetal \\ Facultad de Ciencias Básicas, Pontificia Universidad Javeriana \\ Cra. $7^{a} N^{\circ}$ 43-82, Laboratorio 206 Edificio Jesús Emilio Ramírez \\ Bogotá, D.C., Colombia \\ *marquez.maria@javeriana.edu.co
}

Recibido: 03-07-2008 Aceptado: 05-06-2009

\begin{abstract}
Resumen
Objetivo. Estandarizar un protocolo de extracción de ADN eficiente y preciso para Passiflora ligualaris. Materiales y métodos. Se evaluaron dos métodos de extracción de ADN y dos tipos de tejido de Passiflora ligularis en términos de pureza, calidad y cantidad de ADN obtenido, al igual que su aplicabilidad en técnicas moleculares basadas en PCR como los RAPD (Random Amplified Polymorphic DNA). La cuantificación de ADN se realizó mediante espectrofotometría de absorbancia a una longitud de onda de 260nm (A260) usando el espectrofotómetro Beckman $\mathrm{Du}{ }^{\circledR}$ 530, de igual manera se obtuvo una estimación de la pureza del ADN por medio de la relación de absorbancia $\left(\mathrm{A}_{260 /} \mathrm{A}_{280} \mathrm{~nm}\right.$ ). Las variables analizadas en este estudio fueron: el método de extracción (A) y el tipo de tejido (B), con el fin de definir la influencia que éstas tuvieron en la pureza y cantidad de ADN extraído. Para el estudio de estas variables se usó un diseño aleatorio con arreglo factorial 2 x 2. Resultados. La cantidad promedio de ADN obtenido con el método de Mc Couch et al. (1988) modificado y Doyle \& Doyle (1991) modificado fue $778,9 \mu \mathrm{g} / \mathrm{ml} \mathrm{y} 660,1 \mu \mathrm{g} / \mathrm{ml}$ respectivamente para el tejido seco, para el tejido fresco los promedios fueron $1543,3 \mu \mathrm{g} / \mathrm{ml}$ y $820,4 \mu \mathrm{g} / \mathrm{ml}$ respectivamente. Los dos métodos de extracción con tejido fresco produjeron ADN de buena calidad para la amplificación mediante métodos de PCR como los marcadores RAPD. Conclusión. Teniendo en cuenta los resultados obtenidos se propone que con el método de Mc Couch et al. (1988) y utilizando tejido foliar fresco se obtiene un ADN de óptima calidad para ser utilizado en los marcadores RAPD.
\end{abstract}

Palabras clave: ADN, extracción, Passiflora ligularis, RAPD.

\begin{abstract}
Extraction of high quality DNA of Passiflora ligularis for its analysis with molecular markers. Objective. To standardize a precise and efficient DNA isolation protocol of Passiflora ligularis. Materials and methods. Two methods of DNA extraction and two different tissues of Passiflora ligularis were evaluated in terms of purity, quality and quantity of DNA yield, as well as DNA's suitability for molecular techniques based on PCR such as RAPDs. Quantification of DNA was done using absorbance spectrophotometry at a wavelength of 260nm $\left(\mathrm{A}_{260}\right)$ with a Beckman Du ${ }^{\circledR} 530$ spectrophotometer. An estimate of the DNA's purity was obtained using the absorbance ratio $\left(\mathrm{A}_{260} / \mathrm{A}_{280} \mathrm{~nm}\right)$. The variables analyzed in this study were the extraction method $(\mathrm{A})$ and the tissue type (B), in order to define their influence on the purity and quantity of the DNA extracted. For the study of these variables a random design with a 2 x 2 factorial arrangement was used. Results. The average quantities of DNA obtained with the modified method of Mc Couch et al. (1988) and the modified method of Doyle \& Doyle (1991) method were $778.9 \mu \mathrm{g} / \mathrm{ml}$ and $660.1 \mu \mathrm{g} / \mathrm{ml}$ respectively for dry tissue. Averages with fresh tissue were $1543.3 \mu \mathrm{g} /$ $\mathrm{ml}$ and $820.4 \mu \mathrm{g} / \mathrm{ml}$ respectively. Conclusion. Based upon our results we suggest the use of Mc Couch et al. (1988) method with fresh leaf tissue to obtain a high quality DNA suitable to be used with RAPDs molecular markers.
\end{abstract}

Key words: DNA, extraction, Passiflora ligularis, RAPDs. 


\begin{abstract}
Resumo
Aperfeiçoamento da extração do DNA de Passiflora ligularis para análiße através de marcadores moleculares. Objetivo. Padronizar um protocolo de extração eficiente e preciso do DNA para Passiflora ligularis. Materiais e métodos. Avaliaram-se dois métodos de extração do DNA em dois tipos de tecido de Passiflora ligularis em termos de pureza, qualidade e quantidade do DNA obtido, assim como, sua aplicabilidade em técnicas moleculares baseadas em PCR como os RAPD. A quantificação do DNA realizou-se mediante espectrofotometria de absorbância numa longitude de onda de 260nm (A260) usando o espectrofotômetro Beckman DUß 530, em forma similar, obteve-se uma estimação da pureza do DNA por meio da relação de absorbância $\left(\mathrm{A}_{260 /} \mathrm{A}_{280} \mathrm{~nm}\right)$. As variáveis analisadas neste estudo foram: o método de extração (A) e o tipo de tecido (B), com a finalidade de definir a influência que estas tiveram na pureza e quantidade do DNA extraído. Para o estudo destas variáveis empregou-se um desenho aleatório com arranjo fatorial 2 X 2. Resultados. A quantidade media do DNA obtido com o método de Mc Couch et al (1988) modificado e Doyle \& Doyle (1991) modificado, foi 778,9 $\mu \mathrm{g} / \mathrm{ml}$ y 660,1 $\mu \mathrm{g} / \mathrm{ml}$ respectivamente para o tecido seco; para o tecido fresco as medias foram $1543,3 \mu \mathrm{g} / \mathrm{ml}$ e $820,4 \mu \mathrm{g} / \mathrm{ml}$ respectivamente. Conclusão. Considerando os resultados obtidos propõe-se que com o método de Mc Couch et al (1988) e utilizando tecido folhar fresco obteve-se um DNA de ótima qualidade para ser utilizado nos marcadores RAPD.
\end{abstract}

Palavras chave: DNA, extração, Passiflora ligularis, RAPD.

\section{Introducción}

El conocimiento de la distribución de la variabilidad genética es de suma importancia para el desarrollo de estrategias de conservación efectivas. La variabilidad puede ser muy diferente entre especies y entre poblaciones de una misma especie, el conocimiento de esta variabilidad puede ser de gran interés para programas de selección y mejoramiento de especies con valor comercial y ambiental. Las técnicas de biología molecular y en particular el uso de marcadores moleculares permiten conocer, caracterizar y estimar la diversidad genética y las relaciones entre grupos de interés.

Estudios han demostrado que existen diferentes factores que afectan los perfiles de amplificación obtenidos mediante técnicas moleculares basadas en PCR, lo cual se manifiesta principalmente en la presencia de falsos positivos y la poca reproducibilidad del ensayo (1).

Algunos de los principales factores que afectan estos perfiles de amplificación, son la calidad, pureza y cantidad del ADN extraído, lo cual tiene que ver principalmente con el co-aislamiento de polisacáridos, fenoles y metabolitos secundarios durante la extracción de ADN (2). Las especies de Passiflora se caracterizan por su particular riqueza en metabolitos secundarios como esteroides, alcaloides, gomas, taninos, resinas y algunos ácidos (3) que pueden influir en la calidad de la extracción del ADN.

El objetivo de este estudio fue evaluar dos métodos de colecta y preservación de las muestras vegetales: mantenidas en frío (tejido fresco) y secadas a temperatura ambiente (tejido seco), con dos métodos de extracción de ADN, a partir de hojas de $P$. ligularis, para la obtención de ADN con calidad, pureza y cantidad suficiente para su análisis mediante marcadores moleculares basados en PCR.

\section{Materiales y métodos}

\section{Material vegetal}

Para el estudio, se colectaron hojas de Passiflora ligularis procedentes de fincas productoras del eje cafetero colombiano. Las muestras fueron colectadas, empacadas en sílica gel y almacenadas en frío (tejido fresco) y empacadas en sílica gel y almacenadas a temperatura ambiente (tejido seco). Posteriormente todas las muestras (tejido fresco y seco) fueron trasladadas al laboratorio donde fueron maceradas con nitrógeno líquido y almacenadas a $-70^{\circ} \mathrm{C}$ hasta su utilización.

\section{Métodos de extracción de ADN}

Para los análisis fueron tomadas muestras de hojas de seis plantas diferentes, con las cuales se evaluaron dos protocolos de extracción con los dos tipos de tejido foliar (fresco o seco): Doyle \& Doyle (4) modificado y Mc Couch et al. (5) modificado. En el primer protocolo se usaron 300 mg de tejido foliar macerado (seco y fresco) los cuales fueron puestos en tubos de microcentrífuga (de $2 \mathrm{ml}$ ) con $700 \mu \mathrm{l}$ de buffer de extracción (Tris- $\mathrm{HCl}$ pH.8.0 100 mM, EDTA $20 \mathrm{mM}, \mathrm{NaCl} 1.4 \mathrm{M}, \mathrm{CTAB}(2 \%)$, $\beta$-mercaptoetanol $2 \%$, PVP $1 \%$ ) e incubados a $65^{\circ} \mathrm{C}$ por $30 \mathrm{~min}$. mezclando por inversión. A estas muestras se les añadió $750 \mu \mathrm{l}$ de cloroformo:alcohol isoamílico (v/v) y fueron centrifugadas por $5 \mathrm{~min}$. a $8000 \mathrm{rpm}$

El sobrenadante fue transferido a un nuevo tubo, se añadieron 2/3 de volumen de isopropanol frío y se incubó a $20^{\circ} \mathrm{C}$ durante toda la noche. Las muestras fueron centrifugadas a $15000 \mathrm{rpm}$ durante $5 \mathrm{~min}$, posteriormente el pellet fue lavado con buffer de lavado (etanol 76\%, acetato de amonio $10 \mathrm{mM}$ ), centrifugado a $8000 \mathrm{rpm} \mathrm{du}-$ rante $10 \mathrm{~min}$. y secado a temperatura ambiente. El ADN fue 
resuspendido en $50 \mu \mathrm{l}$ de buffer TE (Tris - $\mathrm{HCl} 10 \mathrm{mM} \mathrm{pH}$ 8,0 , EDTA $50 \mathrm{mM} \mathrm{pH} \mathrm{8,0).}$

En el segundo protocolo los $300 \mathrm{mg}$ de tejido foliar macerado (seco y fresco) fueron puestos en tubos de microcentrífuga $(2 \mathrm{ml})$ con $900 \mu \mathrm{l}$ de buffer de extracción previamente calentado a $65^{\circ} \mathrm{C}$ (Tris- $\mathrm{HCl} \mathrm{pH} 8,0100 \mathrm{mM}$, EDTA $50 \mathrm{mM}$ pH 8,0, NaCl $500 \mathrm{mM}$, SDS 1,25\% p/v, Bisulfito de sodio 0,38\% p/v, â-mercaptoetanol 1,5\% v/ v), incubados a $65^{\circ} \mathrm{C}$ por 30 min. mezclando por inversión. A cada una de las muestras se le adicionó $500 \mu \mathrm{l}$ de acetato de potasio $5 \mathrm{M}$ y fueron incubadas en hielo durante 30 min. con agitación. Posteriormente las muestras fueron centrifugadas a $14000 \mathrm{rpm}$ durante $10 \mathrm{~min}$. El sobrenadante fue transferido a un nuevo tubo y se le adicionaron $500 \mu \mathrm{l}$ de cloroformo, mezclando por inversión durante $5 \mathrm{~min}$. Posteriormente las muestras fueron centrifugadas a $14000 \mathrm{rpm}$ durante $10 \mathrm{~min}$. a $4^{\circ} \mathrm{C}$, el pellet fue resuspendido en $900 \mu \mathrm{l}$ de buffer TE, se le adicionaron $75 \mu \mathrm{l}$ de acetato de sodio $3 \mathrm{M} \mathrm{pH} 5.2$ y $500 \mu \mathrm{lde}$ isopropanol frío y se incubaron $-70^{\circ} \mathrm{C}$ durante $30 \mathrm{~min}$. Las muestras fueron centrifugadas a $14000 \mathrm{rpm}$ durante 10 min. a $4^{\circ} \mathrm{C}$, se descartó el sobrenadante, el pellet de ADN se lavó con $800 \mu \mathrm{l}$ de etanol $70 \%$ (v/v) frío y se centrifugó a $12000 \mathrm{rpm}$ durante $5 \mathrm{~min}$. a $4^{\circ} \mathrm{C}$. El pellet de ADN fue secado a temperatura ambiente y resuspendido en $100 \mu \mathrm{l}$ de buffer TE. Al ADN resuspendido se le agregó un volumen de cloroformo y se centrifugó a 14000 rpm durante $10 \mathrm{~min}$. El sobrenadante fue transferido a un tubo nuevo, se le agregaron 2,5 volúmenes de etanol absoluto y $1 / 10$ de volumen de acetato de amonio $5 \mathrm{M}$ y se incubó a $-20^{\circ} \mathrm{C}$ durante $2 \mathrm{~h}$, después de las cuales fue centrifugado a $14000 \mathrm{rpm}$ durante $10 \mathrm{~min}$. El sobrenadante fue eliminado y el precipitado de ADN fue secado a temperatura ambiente, finalmente el pellet fue resuspendido en $50 \mu \mathrm{l}$ de buffer TE.

\section{Determinación de la calidad, pureza y concentración de ADN extraído:}

Para la determinación de la calidad del ADN de las muestras obtenidas con cada uno de los protocolos, se realizaron electroforesis en gel de agarosa al $0,8 \%(\mathrm{p} / \mathrm{v})$ teñido con bromuro de etidio (BEt) $10 \mu \mathrm{g} / \mathrm{ml}$. Estos geles fueron visualizados en un transiluminador de luz UV y documentados mediante un equipo DocXR System de Biorad $®$.

El ADN se cuantificó por espectrofotometría de absorbancia a una longitud de onda de $260 \mathrm{~nm}$ (A260) usando el espectrofotómetro Beckman Du® 530, a través de este método también se obtuvo una estimación de la pureza del $\mathrm{ADN}$ por medio de la relación de absorbancia $\left(\mathrm{A}_{260} \mathrm{~A}_{280} \mathrm{~nm}\right)$.

\section{Análisis de datos}

Las variables analizadas en este estudio fueron: el método de extracción (A) y el tipo de tejido (B), con el fin de definir la influencia que éstas tuvieron en la pureza y cantidad de ADN extraído.

Para el estudio de estas variables se usó un diseño aleatorio con arreglo factorial $2 \times 2$, el cual tiene el siguiente modelo:

$$
\text { Yijk }=\mu+A+B+A B+\varepsilon
$$

Donde: Yijk es la variable de respuesta, $\mu$ es el efecto medio general, A es el efecto del factor $i$, B es el efecto del factor $j, \mathrm{AB}$ es la interacción del efecto del factor $\mathrm{A}$ con el factor B y $\varepsilon$ es el error experimental.

El análisis de los datos se realizó con el programa Statistical Analysis System, (SAS) v8 (6), utilizando el procedimiento de modelos lineales (GLM). Para el análisis estadístico se realizaron análisis de varianzas y comparación de medias utilizando la prueba de intervalos múltiples de Duncan. Se consideraron significativos los valores de $\mathrm{P}$ menores que $0.01(\mathrm{P}<0.01)$.

\section{Amplificación de ADN (RAPD)}

Con el objetivo de evaluar la calidad del ADN extraído para el análisis preliminar de las muestras de Passiflora ligularis mediante marcadores moleculares RAPD, se usaron los primer OPB 20, OPG 08 y OPAM 10 de Operon Technologies ®. La PCR se llevó a cabo en un termociclador PTC-100 de MJ Research. La mezcla de reacción contenía: buffer para PCR $1 \mathrm{X}, \mathrm{MgCl}_{2} 2,75 \mathrm{mM}$, dNTPs $0,25 \mathrm{mM}$, Taq polimerasa $1 \mathrm{U}$, primer $7 \mu \mathrm{M}$, ADN $30 \mathrm{ng}$ y agua hasta completar un volumen final de $25 \mu \mathrm{l}$. La mezcla de PCR fue sometida al siguiente programa de amplificación: 1 ciclo a $94^{\circ} \mathrm{C}$ por 5 min, 34 ciclos a $94^{\circ} \mathrm{C}$ por $30 \mathrm{seg}, 40^{\circ} \mathrm{C}$ por $30 \mathrm{seg}$, y $72^{\circ} \mathrm{C}$ por $1 \mathrm{~min}$, con una extensión final de $72^{\circ} \mathrm{C}$ por $5 \mathrm{~min}$. Los resultados fueron analizados por electroforesis en gel de agarosa al 1,5\% (p/v), teñidos con bromuro de etidio y visualizados en luz ultravioleta.

\section{Resultados}

\section{Cantidad de ADN}

La cantidad promedio de ADN obtenido con el método de Mc Couch et al. (5) modificado y Doyle \& Doyle (4) modificado fue $778,9 \mu \mathrm{g} / \mathrm{ml}$ y $660,1 \mu \mathrm{g} / \mathrm{ml}$ respectivamente para 
el tejido seco, para el tejido fresco los promedios fueron $1543,3 \mu \mathrm{g} / \mathrm{ml}$ y $820,4 \mu \mathrm{g} / \mathrm{ml}$ respectivamente. En la figura 1 se observa que existe una aparente diferencia entre los métodos evaluados; sin embargo, al realizar el análisis estadístico por medio de la prueba de comparación de medias de Duncan, se evidencia que no existen diferencias estadísticamente significativas entre los métodos evaluados $(\mathrm{p}<0,38)(\mathrm{p}<0,056)($ Tabla 1).

Al realizar el análisis para el tipo de tejido utilizado en los dos métodos de extracción se obtuvieron diferencias significativas $(\mathrm{P}<0.05)$ entre el tejido fresco y el tejido seco respecto a la cantidad (Tabla 1), lo que lleva a plantear que el tipo de tejido es el que presenta una mayor incidencia en la cantidad de ADN obtenido.

\section{Pureza del ADN}

Método de extracción de ADN: para esta variable no se obtuvieron diferencias significativas entre el método de Mc Couch et al. (5) modificado y Doyle \& Doyle (4) modificado, el promedio de la pureza obtenida con cada método fue de $\mathrm{A}_{260} / \mathrm{A}_{280}=1.41 \mathrm{y} \mathrm{A}_{260} / \mathrm{A}_{280}=1.34$ respectivamente, con tejido seco (Figura 2). El promedio para el tejido fres-

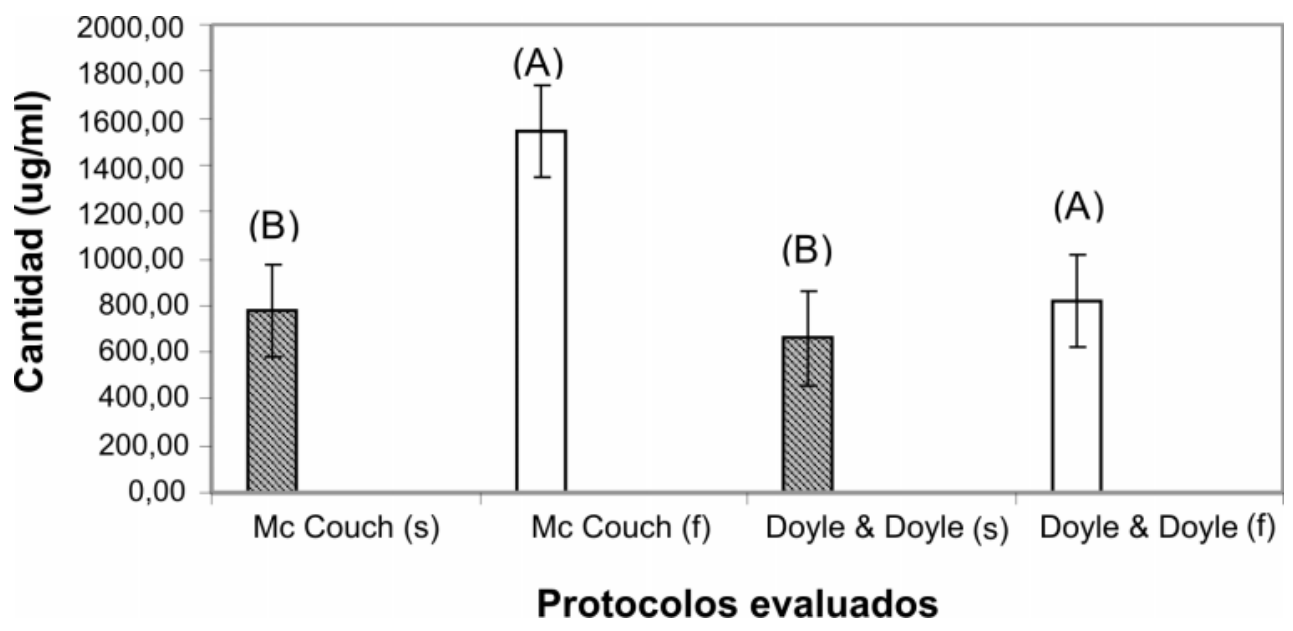

Figura 1. Concentración de ADN de Passiflora ligularis obtenida a partir de dos tipos de tejido (Seco (s) y fresco (f)). A y $\mathrm{B}$ indican las agrupaciones según la prueba de Duncan. Los datos son el promedio de 10 repeticiones

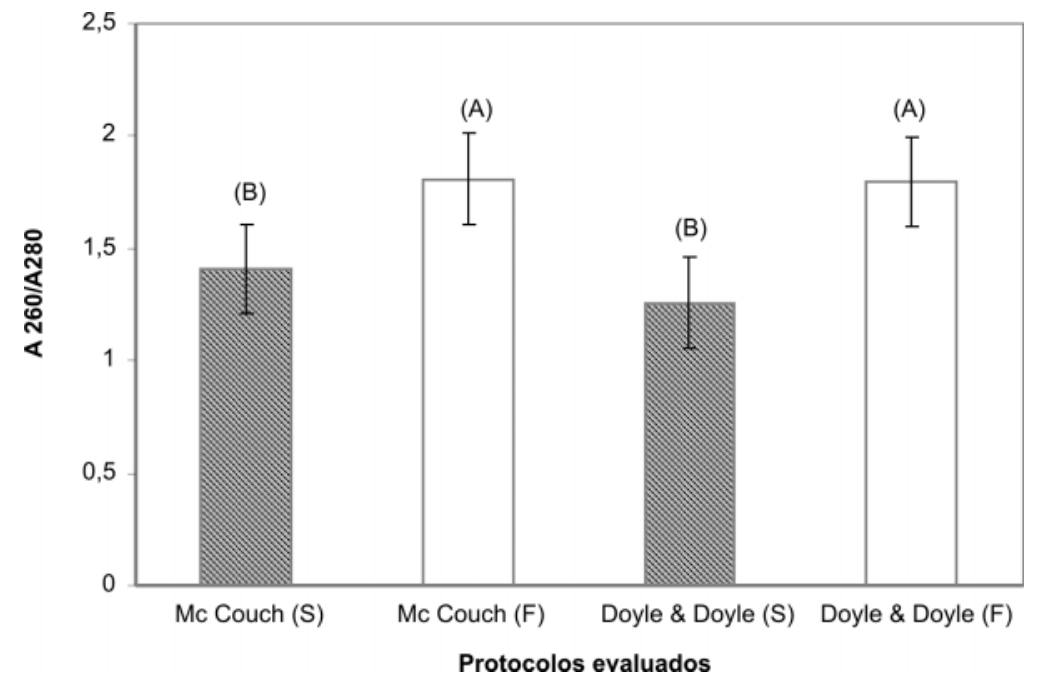

Figura 2. Pureza de ADN de Passiflora ligularis obtenida a partir de dos tipos de tejido (seco (s) y fresco (f)). A y B indican las agrupaciones según la prueba de Duncan. Los datos son el promedio de 10 repeticiones 
co para el método de Mc Couch et al. (5) fue de $\mathrm{A}_{260} / \mathrm{A}_{280}$ $=1,8$ y para Doyle $\&$ Doyle (4) fue de $\mathrm{A}_{260} / \mathrm{A}_{280}=1.79$ (Figura 2). Esto deja nuevamente en evidencia que el tipo de método de extracción tiene poca influencia en la pureza del ADN obtenido, mientras que el tipo de tejido utilizado si presenta una gran incidencia en la pureza, esto se comprueba al realizar el análisis estadístico, en donde el tejido seco y fresco presenta diferencias estadísticamente significativas $(\mathrm{P}<0.01)$ (Tabla 1$)$.

Al realizar la prueba de comparación de medias de Duncan para la pureza y cantidad de $\mathrm{ADN}$, se obtuvo que no existe una diferencia estadísticamente significativa entre los métodos utilizados para la extracción de ADN $(\mathrm{p}<0,38)$
( $p<0,056)$, ni en la interacción del método y el tejido $(\mathrm{p}<0,56)$ $(\mathrm{p}<0,165)$; sin embargo, al tener en cuenta el tipo de tejido se encontró una diferencia estadísticamente significativa $(p<0,001)(p<0,036)$. En la tabla 1 se observa la influencia de cado uno de los factores evaluados (método de extracción y tipo de tejido) para la pureza y cantidad de ADN.

\section{Calidad del ADN}

Teniendo en cuenta los resultados del análisis estadístico, se evaluó la integridad del ADN obtenido con tejido fresco. La figura 3 evidencia que no existe una diferencia en la integridad del ADN de Passiflora ligularis obtenido con los dos protocolos evaluados.

Tabla 1. Incidencia de los distintos factores (método y tipo de tejido) y sus interacciones con la pureza y cantidad de ADN extraído según el modelo factorial

\begin{tabular}{lcc}
\hline & \multicolumn{2}{c}{ Variables de respuesta } \\
\cline { 2 - 3 } & \multicolumn{2}{c}{ Componentes de varianza (\%) } \\
\hline Fuente de variación & Pureza & Cantidad \\
\hline Método & 1,07 & 36,76 \\
Tejido & $98,46^{* * *}$ & $44,30 *$ \\
Método x tejido & 0,47 & 18,94 \\
\hline
\end{tabular}

$* \mathrm{P}<0,05$

$* * * \mathrm{P}<0,001$

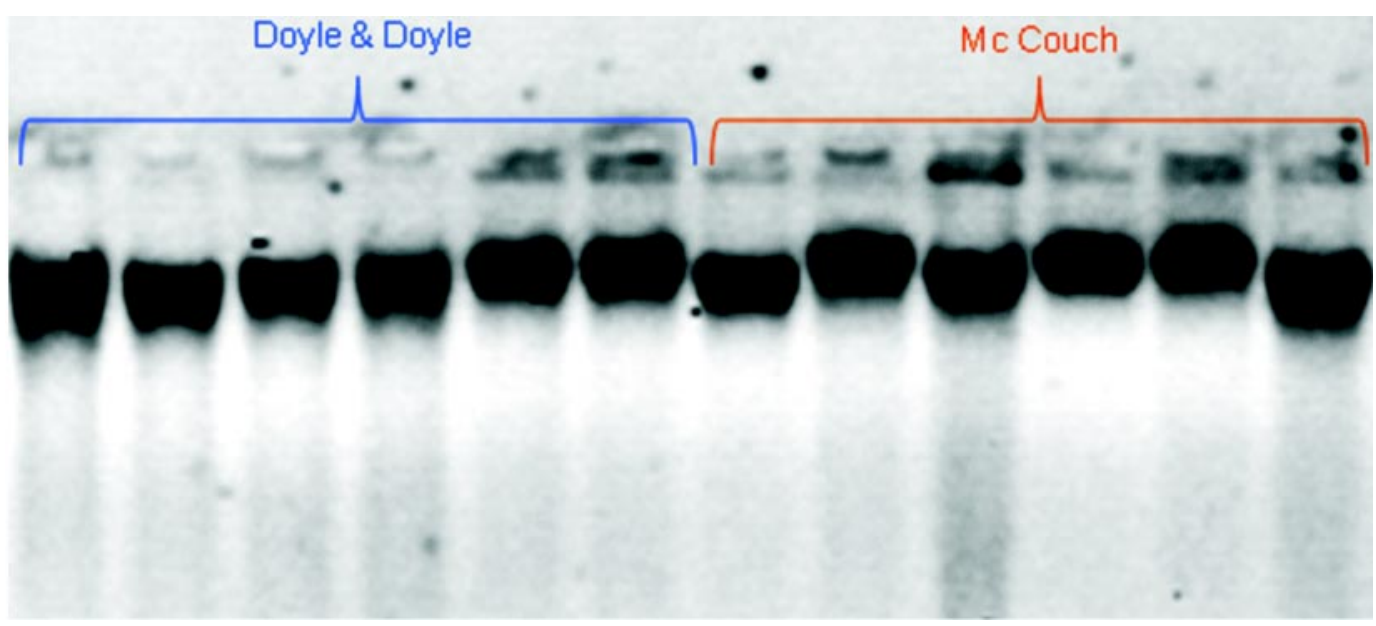

Figura 3. Gel de agarosa al $0,8 \%$ donde se observa la calidad de ADN extraído de Passiflora ligularis con tejido fresco y los diferentes protocolos evaluados. 
Los resultados obtenidos sugieren que para la extracción eficiente de ADN de Passiflora ligularis debe ser utilizado tejido fresco independientemente del método de extracción, pues ambos métodos ofrecen buenos resultados en cuanto a las variables evaluadas.

De manera general los dos métodos de extracción con tejido fresco produjeron ADN de buena calidad para la amplificación mediante métodos de PCR, para la amplificación por medio de marcadores moleculares RAPD (Figura 4); sin embargo se escogió el ADN obtenido por el protocolo de Mc Couch et al. (5) modificado, debido a que se obtiene relativamente mayor cantidad de ADN.

\section{Discusión}

El desarrollo de métodos moleculares ha llevado a la necesidad de desarrollar metodologías de extracción de ADN más simples y eficientes pero a su vez adaptadas a las especies de trabajo. El tipo o condiciones de almacenamiento del tejido utilizado, variantes en la eficiencia de la lisis y en la remoción de contaminantes (proteínas, polisacáridos y componentes fenólicos, etc.) influyen en el rendimiento y la pureza de ADN y a su vez pueden afectar los resultados de técnicas moleculares como la PCR (2).

En el presente estudio el tipo de tejido empleado (seco o fresco) fue la variable que estadísticamente tuvo mayor incidencia en la pureza y cantidad del ADN extraído, mostrando diferencias significativas; mientras que los métodos de extracción de ADN no mostraron diferencias significativas, es decir, que ambos métodos fueron eficientes para la extracción de ADN de P. ligularis.

Hills et al. (7) plantearon que la utilidad o ventaja de un protocolo de extracción de ADN con respecto a otros está directamente relacionada con el método de preservación del material inicial (fresco, seco o congelado), lo cual tiene una gran incidencia a la hora de obtener un ADN de alta pureza y cantidad, suficiente para el desarrollo de marcadores moleculares basados en PCR. De manera similar, el estado sanitario, fisiológico y químico de las muestras, inciden en la pureza y cantidad del $\operatorname{ADN}(8)$.

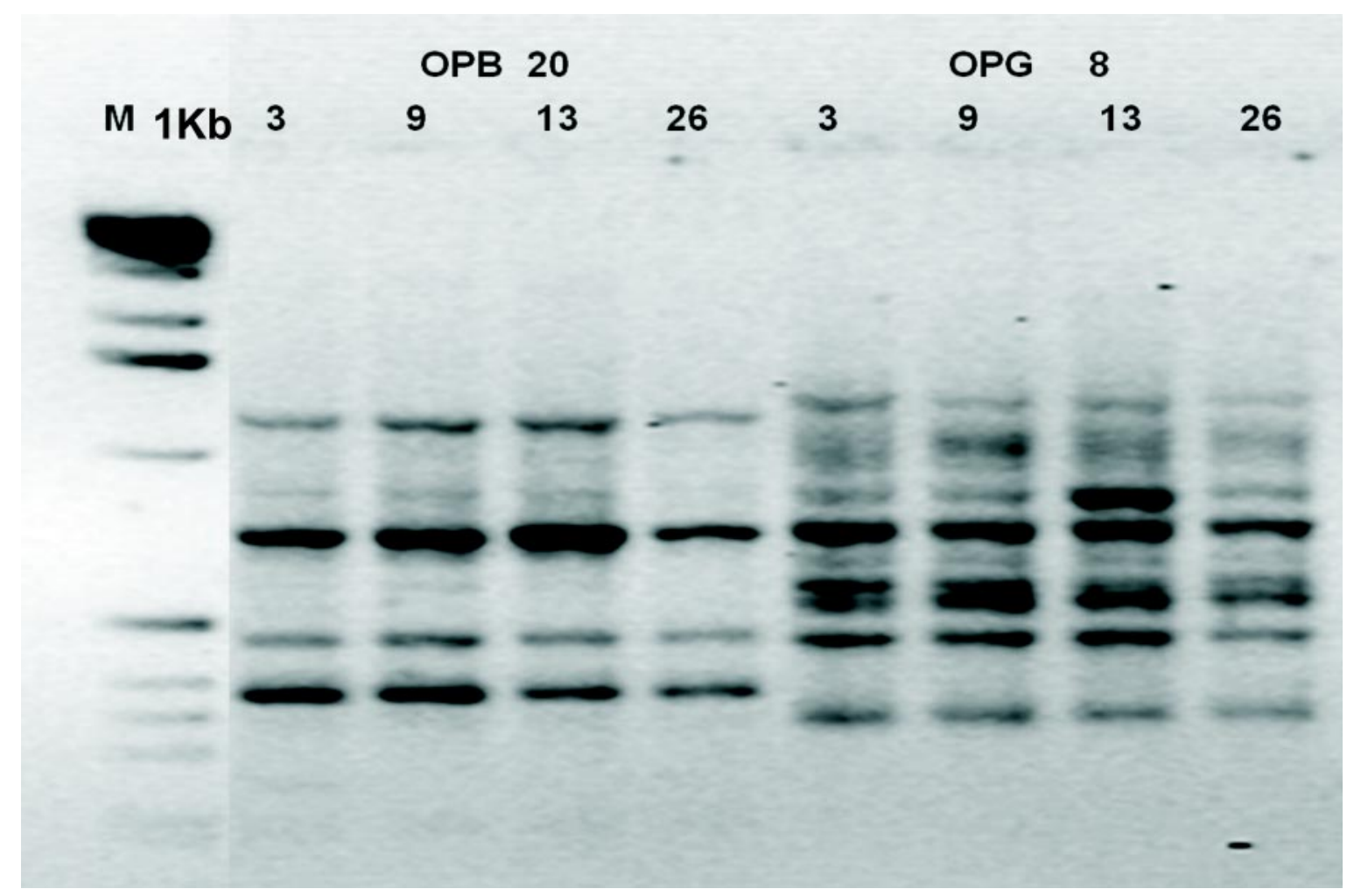

Figura 4. Perfil electroforético de los productos de amplificación mediante RAPD. Se evaluaron muestras de ADN de P. ligularis extraído mediante el método de Mc Couch et al. (1988), con tejido fresco, amplificados con los primers OPB 20 y OPG 8. 


\section{Conclusiones}

Los resultados de este estudio sugieren que la obtención de ADN genómico de P. ligularis de buena calidad y pureza depende directamente del método de colecta y preservación del material vegetal, hojas jóvenes colectadas y empacadas en sílica gel y conservadas en frío produjeron los mejores resultados; mientras que el método o protocolo de extracción utilizado no influyó en la calidad y pureza del ADN extraído.

\section{Agradecimientos}

Los autores agradecen al Centro de Investigaciones y Estudios en Biodiversidad y Recursos Genéticos - CIEBREG, a Colciencias y a la Pontificia Universidad Javeriana donde se realizó la investigación.

\section{Financiación}

Centro de Investigaciones y Estudios en Biodiversidad y Recursos Genéticos - CIEBREG

(Proyecto: Valoración de los bienes y servicios de la biodiversidad para el desarrollo sostenible de paisajes rurales colombianos: Complejo Ecorregional Andes del Norte) y Conciencias.

\section{Conflictos de intereses}

Los autores declaran que no existen conflictos de intereses

\section{Referencias}

1. Atienzar F, Evenden A, Jha A, Savva D, Depledge M. Optimized RAPD analysis generates high quality genomic ADN profiles at high annealing temperature. Biotechniques 2000; 28: 52-54.

2. Molinari HB, Crochemore ML. Extração de DNA genômico de Passiflora spp para análisis PCR-RAPD. Revista Brasileira de Fruticultura, Jaboticabal - SP 2001; 23 (2): 447- 450.

3. Duke JA. Handbook of Medical Herbs. CRC Press. Boca Raton. Florida. 1989; 667 p.

4. Doyle JJ, Doyle JL. Isolation of plant DNA from fresh tissue. Focus 1991; 1, 13-15.

5. Mc Couch SR, Kochert G, Yo ZH, Wang ZY, Khush GS, Coffman WR, Tanksley SD. Molecular mapping of rice chromosomes. Theoretical and Applied Genetics 1988; 76, 815- 829.

6. SAS Institute. Statistical Analysis System - SAS V.8. 2001.

7. Hills DM, Mortiz C. Molecular Systematics. Sinauer Associates, INC Publishers. Sunderland, Massachusetts. USA. 1990; 238 p.

8. Michiels A, Endea V, Tuckerb M, Liesbet V, Laerea A. Extraction of high-quality genomic DNA from latex-containing plants. Analytical Biochemistry. USA. 2003; 1, 85-89. 